\title{
Comorbidities of Atopic Dermatitis: Beyond Rhinitis and Asthma
}

\author{
Yuki M.F. Andersen ${ }^{1} \cdot$ Alexander Egeberg $^{1} \cdot \operatorname{Lone~Skov~}^{1} \cdot$ Jacob P. Thyssen $^{1}$
}

Published online: 21 January 2017

(C) Springer Science+Business Media New York 2017

\begin{abstract}
Purpose of Review In this review article, we summarize the current evidence about atopic dermatitis (AD)-associated comorbidities, beyond the traditional atopic and allergic conditions.

Recent Findings Patients with AD may have an increased risk of cardiovascular diseases, certain malignancies, autoimmune diseases, and neuropsychiatric diseases. The causes of these associations are likely multifactorial and may include genetic predispositions, systemic low-grade inflammation, environmental exposures, medication, and lifestyle and behavioral risk factors. There appears to be geographical variations in prevalence of comorbidities in patients with $\mathrm{AD}$, indicating that differences in ethnicity and lifestyle factors may significantly influence the risk of certain comorbidities.

Summary The reported comorbidities in recent literature emphasize the burden of disease in patients with AD. Early appropriate $\mathrm{AD}$ therapy, in combination with reduction of risk factors, may help prevention of certain comorbidities. The reported observations may generate hypotheses for future investigations in underlying risk factors for $\mathrm{AD}$-associated comorbidities.
\end{abstract}

Keywords Atopic dermatitis · Comorbidities ·

Cardiovascular disease $\cdot$ Cancer $\cdot$ Autoimmune disease .

Neuropsychiatric disease

This article is part of the Topical Collection on Atopic Dermatitis

Jacob P. Thyssen

Jacob.p.thyssen@regionh.dk

1 Department of Dermatology and Allergy, Herlev and Gentofte Hospital, University of Copenhagen, Kildegårdsvej 28,

2900 Hellerup, Denmark

\section{Introduction}

Atopic dermatitis (AD) is a chronic and recurrent inflammatory skin disease, with a lifetime prevalence estimated at 10 $20 \%$ in industrialized countries $[1,2,3 \cdot \bullet]$. While the incidence has increased over the past half century, a recent stagnation in $\mathrm{AD}$ incidence has been reported in several industrialized countries $[2,4,5]$. The etiopathogenesis of $\mathrm{AD}$ is complex and multifactorial, with genetic predisposition, skin barrier dysfunction, altered immune responses, and environmental and lifestyle factors, being suspected as the underlying and aggravating factors [3••]. Disease onset predominately occurs in childhood, and while many outgrow their condition, 5-50\% experience persistent disease into adulthood $[6,7]$.

While relationships between $\mathrm{AD}$ and atopic disorders such as food allergies, allergic asthma, and rhinitis are wellestablished and likely causal [8], research in the burden of non-atopic AD comorbidities has gained significant momentum in recent years. Not only it is essential for physicians and affected patients and families to understand the entire AD spectrum, but discovery of associated comorbidities may also enhance insights into AD pathophysiology and indication for therapy. This review article provides an overview of recent discoveries in non-atopic comorbidities related to AD in children and adults.

\section{Cardiometabolic Diseases in Atopic Dermatitis}

A recent meta-analysis based on 30 studies found a positive association between overweight/obesity and AD in North American and Asian populations, but not in European studies $[9 \bullet \bullet$. Along this line, a large US population-based survey showed that adults with AD had higher odds of hypertension, cigarette smoking, alcohol consumption, respectively, and lower odds of daily vigorous activity compared to the general 
population [10•]. Moreover, US children with moderate to severe AD were found to have increased central obesity and higher blood pressure [11]. However, a significantly reduced prevalence and risk of gallstones compared to controls was observed in Danish adults with $\mathrm{AD}$, indicating that patients with $\mathrm{AD}$ are likely to have normal weight in Europe [12]. In support of this observation, a Swedish questionnaire study found that patients with $\mathrm{AD}$ had the same level of physical exercise as general population controls, again highlighting an apparent difference between the constitution of American and European $\mathrm{AD}$ patients when compared to their respective general population controls [13].

In recent years, epidemiologic AD studies with cardiovascular outcomes such as myocardial infarction (MI) and ischemic stroke have found somewhat opposing results. A large US population-based study reported positive associations between $\mathrm{AD}$ and coronary artery disease, angina, heart attack, congestive heart failure, ischemic stroke, and peripheral vascular disease, respectively [14••]. Similarly, a Danish prospective cohort study found an overall increased risk of MI albeit that the study lacked adjustment for important confounding factors, e.g., smoking [15]. When studying 31 Danish patients with moderate-to-severe AD and 33 healthy control subjects, respectively, patients with $\mathrm{AD}$ had an increased prevalence of subclinical coronary artery disease using cardiac computed tomography angiography [16•]. A Taiwanese cohort study showed a significantly increased risk of ischemic stroke, but not of MI, in patients with $\mathrm{AD}$ [17]. In contrast to the above findings, $\mathrm{AD}$ was not independently associated with nonfatal MI or stroke in a cohort from the Nurses' Health Study 2 [18]. Furthermore, in a Danish population-based study, patients with severe $\mathrm{AD}$ had an increased risk of ischemic stroke and cardiovascular death, but after adjustment for modifiable cardiovascular risk factors such as hypertension and smoking, the risk was similar to matched controls. Interestingly, the study also showed that the risk of cardiovascular outcomes was reduced in patients with mild $\mathrm{AD}$, possibly explained by socioeconomic characteristics that were not accounted for in the study [19•]. Similarly, a recent large German study found a modestly increased risk of angina, hypertension, and peripheral artery disease, but not for myocardial infarction and stroke. The study furthermore failed to identify any shared genetic risk variants for $\mathrm{AD}$ and cardiovascular disease [20]. While it remains unclear whether $\mathrm{AD}$ is associated with increased risk of cardiovascular disease, the prevalence and risk was much smaller than for patients with psoriasis in two European studies [21, 22].

Few studies have focused on type 2 diabetes in AD. A US study found that the presence of $\mathrm{AD}$ in adulthood was associated with higher odds of pre-diabetes, diabetes, and adult onset diabetes, respectively [10•]. In a Danish general population study, both individuals with a history of $\mathrm{AD}$ and individuals with a loss-of-function mutation in the filaggrin gene were significantly associated with having type 2 diabetes, but no information on corticosteroid use was available [23]. Notably, certain anti-AD therapies, but not $\mathrm{AD}$ itself, were found to be independent risk factors for type 2 diabetes in a recent Danish nationwide cohort [24]. A possible link between $\mathrm{AD}$ and type 2 diabetes is likely multifactorial and possibly explained by genetic predisposition [25], sedentary lifestyle [10•], systemic low-grade inflammation [26], and AD-associated therapies including corticosteroids [27].

The discrepancies between the abovementioned results may at least in part be explained by differences in study designs, heterogeneous patient characteristics, the selected covariates included in the analyses, and the quality of available data. Although the cardiovascular risk in AD remains controversial, one potential explanation is based on the theory of shared inflammatory pathways between atherosclerosis and $\operatorname{AD}[28,29]$. A more plausible explanation, however, is that cardiometabolic comorbidities are driven by the overall disease burden in patients with AD. For example, pruritus, a reduced quality of life and psychological stress associated with AD may result in poor health behaviors including physical inactivity and smoking, which in turn can increase morbidity and mortality (Fig. 1). A recent Danish study found a higher prevalence of smoking-related outcomes in patients with severe $\mathrm{AD}$, including chronic obstructive pulmonary disease, suggesting that smoking could represent a significant cardiovascular risk factor in patients with $\mathrm{AD}$ as well (manuscript submitted). Similarly, a large meta-analysis showed a strong association between tobacco smoking and $\mathrm{AD}[30]$.

\section{Cancer and Atopic Dermatitis}

The association between $\mathrm{AD}$ and cancer is unresolved. Studies investigating the association between $\mathrm{AD}$ and malignant melanoma (MM) have either found an inverse association or non-significant results, while studies on nonmelanoma skin cancers, i.e., basal cell carcinoma (BCC) and squamous cell carcinoma (SCC), have trended towards positive associations with $\mathrm{AD}$ in some [31-33] but not all studies $[34,35]$. A recent systematic review and meta-analysis based on 18 independent studies found that $\mathrm{AD}$ was not associated with MM or SCC, but significantly associated with BCC [36]. The authors emphasized that due to the heterogeneity in included covariates such as sun-exposure, ethnicity, and use of immunosuppressant therapy, solid conclusions on the independent risk associated with $\mathrm{AD}$ could not be made [36]. Sun-exposure and possibly phototherapy are major risk factors in the development of skin cancers, and although speculative, impaired skin barrier function in patients with $\mathrm{AD}$ may play a role in a possible association [37]. Indeed, ADassociated reduction or absence of epidermal filaggrin could, at least in theory, allow for higher penetration rates of ultraviolet B photons and cause DNA damage, and in turn, 


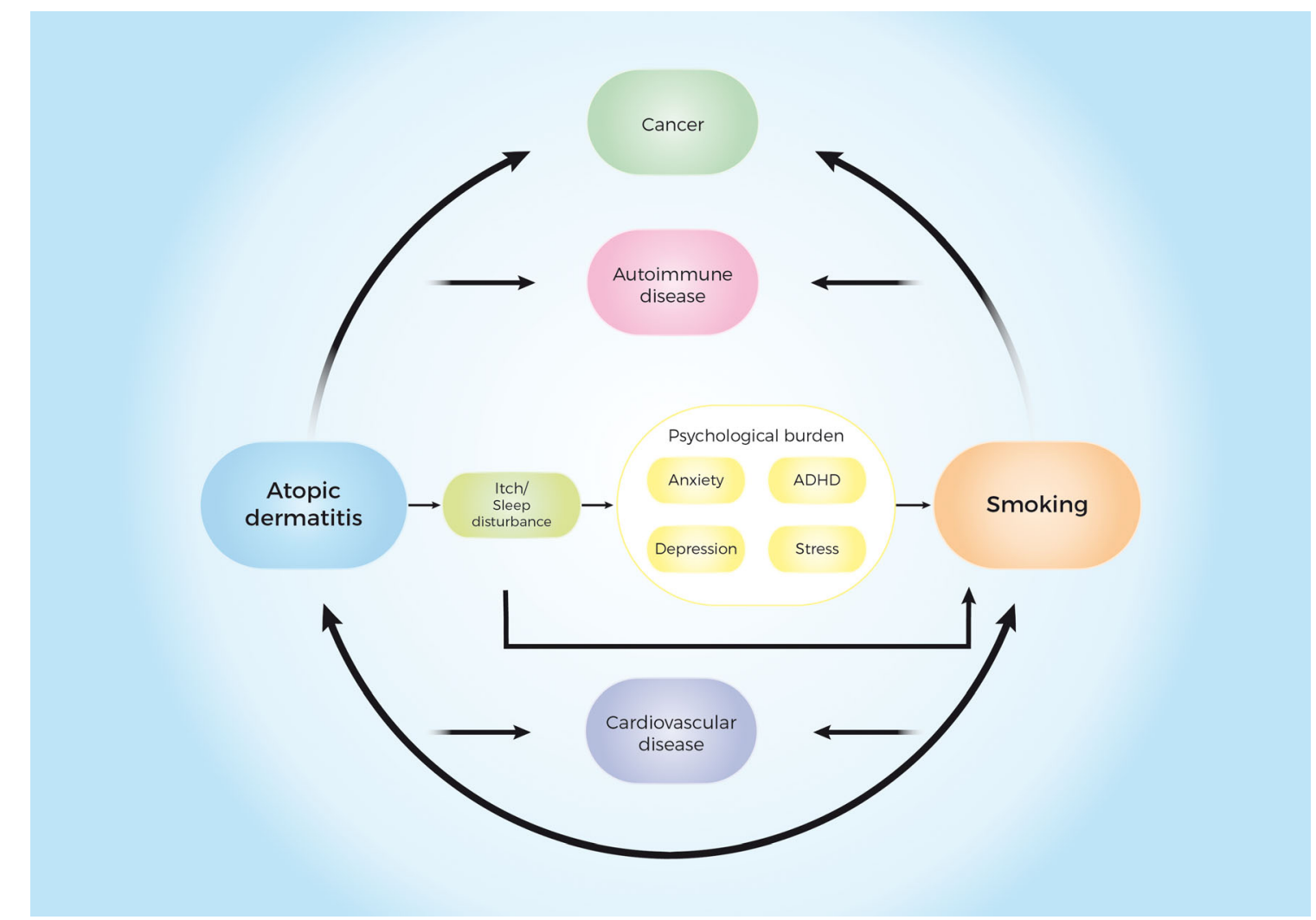

Fig. 1 Putative role of tobacco smoking in the development of comorbidities associated with atopic dermatitis. The figure represents a simplified model of how tobacco smoking may influence the increased

malignancy [38, 39]. Another possible risk factor that may contribute to the risk of skin cancer is AD-associated immunosuppressant therapy; however, this relationship is still unresolved [40, 41].

A systematic review and meta-analysis found an increased relative risk of lymphoma in patients with $\mathrm{AD}$ and suggested that severity of $\mathrm{AD}$ was a significant risk factor [42••]. The possible association could be driven by a number of factors including genetic predisposition, chronic inflammation, and inappropriate immune skewing from possible tumorprotective properties of Th-1 responses [43]. Furthermore, some studies have shown that chronic exposure to systemic and topical immunosuppressive drugs may increase the risk of lymphoma [42••]. Importantly, however, in observational studies of uncommon conditions, misclassification may occur, and since there is a diagnostic overlap between severe AD and, e.g., cutaneous T cell lymphoma, this could introduce a risk of false positive statistical associations [44]. A metaanalysis based on 10 publications found an inverse association between childhood AD and acute lymphoblastic leukemia. One hypothesis to support the finding is a possible augmented immune surveillance due to increased vigilance of the immune system that could protect against malignant cells [45].

Glioma and meningioma have also been inversely associated with $\mathrm{AD}$ in three systematic review articles [46-48]. prevalence of comorbidities associated with atopic dermatitis. $A D H D$ attention deficit hyperactivity disorder

Although the possible protective mechanisms are unknown, the immune surveillance hypothesis as well as genetic and/or environmental factors has been suggested [46]. For other cancers, the literature is scarce. In a case-control study, a history of $\mathrm{AD}$ was more common in patients with a positive test for high-risk human papilloma virus (HPV) infection in the cervix compared with test negative controls [49]. Filaggrin mutations have been suggested to increase the risk of HPV infections in the cervical mucosa, and are associated with fivefold increased mortality in patients with cervical cancer [50, 51]. Pancreatic cancer has also been studied in observational studies, but the results are conflicting, and the relationship is not yet established [33, 52, 53]. Tobacco smoking is a wellestablished carcinogenic factor in a number of malignancies including cervical, pancreatic, and hematological cancers and could therefore contribute to the observed associations [54-56].

\section{Autoimmune Diseases and Atopic Dermatitis}

Autoimmune diseases affect a wide range of organ systems and are often caused by a complex interplay between genetic predisposing factors and environmental trigger factors [57]. $\mathrm{AD}$ has been associated with both alopecia areata, vitiligo, [58] lupus erythematosus, and chronic urticaria [59, 60]. 
Positive associations have repeatedly been demonstrated between $\mathrm{AD}$ and inflammatory bowel disease $[60,61,62 \bullet, 63]$, celiac disease $[60,64,65]$, systemic lupus erythematosus [59, $60,66,67]$, while results have been conflicting for rheumatoid arthritis $[59,60,62 \cdot, 68]$. Based on the Th- $1 /$ Th-2 dichotomy theory, it was previously believed that diseases such as multiple sclerosis (MS) and type 1 diabetes were inversely associated with $\mathrm{AD}$, as these are dominated by a heightened Th-1 response [69, 70]. However, recent meta-analyses have failed to identify associations between $\mathrm{AD}$ and type 1 diabetes or MS [69, 70]. Other possible autoimmune comorbidities include autoimmune thyroid disease $[59,60,71]$ and autoimmune nephropathy [60, 72-74], although the number of studies are limited and results are inconsistent.

Several links can be drawn between $\mathrm{AD}$ and autoimmune diseases, and the associations are likely explained by multiple causal pathways and cascades. First, patients with $\mathrm{AD}$ may be genetically predisposed to develop certain autoimmune diseases. A recent large genome-wide association study identified multiple susceptibility loci for AD, associated with immune regulation and autoimmunity [75••]. Several autoimmune diseases also tend to cluster, possibly explained by the genetic risk loci distributed among multiple diseases [76]. Second, the increased pro-inflammatory activation in patients with $\mathrm{AD}$, which also involves the blood compartment, might influence the risk of autoimmunity [77]. Accumulating evidence also suggests that patients with AD display autoreactive tendencies, i.e., immune responses to autologous tissue, cells or proteins [77]. Third, environmental exposures may also trigger autoimmune diseases, including tobacco smoking (and other lifestyle factors) [60, 78, 79].

\section{Neuropsychiatric Disorders and Atopic Dermatitis}

Beyond the somatic comorbidities, $\mathrm{AD}$ has been associated with a range of neurologic, psychiatric, and psychological conditions. Depression and anxiety have significantly associated with severity of AD symptoms [80-82]. Notably, a higher risk of suicidal ideation has been observed in patients with $\mathrm{AD}$ [83-85], and a Danish cohort study found an increased risk of completed suicides in adult patients with hospital-diagnosed AD [86]. While AD may confer depressive symptoms [87], psychological stress also appears to trigger AD symptoms in some cases [88]. Thus, the association is likely bidirectional and possibly maintained by the burden of $\mathrm{AD}$ including sleep disturbance, social stigma, increased financial costs, and overall reduced quality of life [89-92].

Cumulative evidence also suggests an association between $\mathrm{AD}$ and pediatric neuropsychiatric conditions. A recent systematic review including 12 articles investigating the association between $\mathrm{AD}$ and attention deficit hyperactivity disorder (ADHD) concluded that the majority of published studies report a positive association between the two conditions [93•]. Furthermore, a systematic review article on the association between $\mathrm{AD}$ and autism spectrum disorder (ASD) based on 18 publications suggested a positive relationship [94]. The link between AD and neuropsychiatric disorders may partly be explained by the psychological stress and sleep deprivation associated with $\mathrm{AD}$; however, certain biochemical pathways have also been suspected to be involved. The increased levels of pro-inflammatory cytokines in children with AD may impact behavioral and emotional functions in the brain by directly passing the bloodbrain barrier; however, this remains to be proven [95•]. Other hypotheses suggest that the chronic inflammation in AD may cause changes in the metabolism of neurotransmitters or affect the hypothalamus-pituitary-adrenal axis [95•]. Lastly, common environmental triggers including perinatal factors may contribute the observed co-occurrence of these diseases in children [96].

\section{Conclusions}

The increasing number of studies published in the past decade has enabled discovery of several previously unrecognized non-atopic comorbidities. Collectively, patients with $\mathrm{AD}$ appear to have an increased risk of cardiovascular disease, certain cancers, as well as a range of autoimmune and neuropsychiatric diseases. Most AD-associated comorbidities are likely caused by a complex interaction between genetic predisposition, environmental exposures, inflammation due to $\mathrm{AD}$, medication, and lifestyle factors. Although observational studies may help detect possible associations, they are primarily hypothesis generating. In most epidemiological studies, causal inference cannot be made due to limitations such as lack of temporality, bias, and confounding factors that are either unavailable or unknown. Another important aspect when interpreting epidemiological findings is to differentiate between absolute and relative risks. Although a statistical association may be significant, when investigating occurrence of diseases, the absolute risks can be low. For example, cardiovascular diseases appear to represent a significantly heavier burden in patients with psoriasis than patients with $\mathrm{AD}$ [22]. It is therefore important to put the data into clinical perspective when interpreting statistical findings.

Conclusively, the recently discovered AD-associated comorbidities emphasize the burden of $\mathrm{AD}$ in both pediatric and adult patients. While many of the underlying mechanisms of associated comorbidity are not yet fully understood, both $\mathrm{AD}$ itself as well as lifestyle factors may contribute to their genesis. We propose that early appropriate AD therapy, in combination with reduction of risk factors, may help prevention of certain comorbidities. Further translational research will improve the understanding of $\mathrm{AD}$-associated comorbidities. 
Compliance with Ethical Standards The manuscript is not under consideration elsewhere. None of the manuscript contents have been previously published in any form. The figure is original. All authors have contributed to the manuscript and approved the submitted version.

Conflict of Interest Jacob Thyssen and Yuki Andersen are supported by an unrestricted grant from the Lundbeck Foundation. Jacob Thyssen has participated in international and national advisory board meetings for Sanofi-Genzyme and Roche. Alexander Egeberg has received research funding from Pfizer and Eli Lilly, and honoraria as consultant and/or speaker from Pfizer, Eli Lilly, Novartis, Galderma, and Janssen Pharmaceuticals. Lone Skov has performed clinical trial for Regeneron, participated in advisory board meetings for Sanofi, and is supported by a grant from the Capital Region of Denmark, Foundation for Health Research.

This work was performed independently through the authors' academic university and hospital affiliations.

Human and Animal Rights and Informed Consent This article does not contain any studies with human or animal subjects performed by any of the authors.

\section{References}

Papers of particular interest, published recently, have been highlighted as:

- Of importance

•- Of major importance

1. Taylor B, Wadsworth M, Wadsworth J, Peckham C. Changes in the reported prevalence of childhood eczema since the 1939-45 war. Lancet. 1984;324:1255-7.

2. Deckers IAG, McLean S, Linssen S, Mommers M, van Schayck $\mathrm{CP}$, Sheikh A. Investigating international time trends in the incidence and prevalence of atopic eczema 1990-2010: a systematic review of epidemiological studies. PLoS One. 2012;7:e39803.

3.• Weidinger S, Novak N. Atopic dermatitis. Lancet. 2016;387:110922. This article provides a comprehensive overview of clinical features, disease mechanisms and management of atopic dermatitis.

4. Henriksen L, Simonsen J, Haerskjold A, Linder M, Kieler H, Thomsen SF, Stensballe LG. Incidence rates of atopic dermatitis, asthma, and allergic rhinoconjunctivitis in Danish and Swedish children. J Allergy Clin Immunol. 2015;136:360-366.e2.

5. Williams H, Stewart A, von Mutius E, Cookson W, Anderson HR. Is eczema really on the increase worldwide? J Allergy Clin Immunol. 2008;121:947-54.e15.

6. Kim JP, Chao LX, Simpson EL, Silverberg JI. Persistence of atopic dermatitis (AD): a systematic review and meta-analysis. J Am Acad Dermatol. 2016;75:681-687.e11.

7. Margolis JS, Abuabara K, Bilker W, Hoffstad O, Margolis DJ. Persistence of mild to moderate atopic dermatitis. JAMA dermatology. 2014;150:593-600.

8. Zheng T, Y J, Oh M, Zhu Z. The atopic march: progression from atopic dermatits to allergic rhinitis and asthma. Allergy Asthma Immunol Res. 2011;3:67-73.

9.• Zhang A, Silverberg JI. Association of atopic dermatitis with being overweight and obese: a systematic review and metaanalysis. J Am Acad Dermatol. 2015;72:606-16. This metaanalysis highlights differences in the prevalence of adiposity in European versus Asian and US atopic dermatitis populations.

10. Silverberg JI, Greenland P. Eczema and cardiovascular risk factors in 2 US adult population studies. J Allergy Clin Immunol. 2015;135:721-728.e6. This large population-based study investigates the prevalence of a range of cardiovascular risk factors in patients with $\mathrm{AD}$ in the US.

11. Silverberg JI. Atopic disease and cardiovascular risk factors in US children. J Allergy Clin Immunol. 2015; doi:10.1016/j. jaci.2015.09.012.

12. Egeberg A, Andersen YMF, Gislason GH, Skov L, Thyssen JP. Difference in gallstone risk in adult patients with atopic dermatitis and psoriasis - the possible effect of overweight and obesity. Venereol: Acta Derm ; 2016.In press

13. Lonne-Rahm S, Sundström I, Nordlind K, Engström L. Adult atopic dermatitis patients and physical exercise: a Swedish questionnaire study. Acta Derm Venereol. 2014;94:185-7.

14.• Silverberg JI. Association between adult atopic dermatitis, cardiovascular disease, and increased heart attacks in three populationbased studies. Allergy Eur J Allergy Clin Immunol. 2015;70:1300 8 . This study reports the risk of major cardiovascular outcomes in three US cohorts.

15. Riis JL, Vestergaard C, Hjuler KF, Iversen L, Jakobsen L, Deleuran MS, Olsen M. Hospital-diagnosed atopic dermatitis and long-term risk of myocardial infarction: a population-based follow-up study. BMJ Open. 2016;6:e011870.

16. Hjuler KF, Böttcher M, Vestergaard C, Deleuran M, Raaby L, Bøtker HE, Iversen L, Kragballe K. Increased prevalence of coronary artery disease in severe psoriasis and severe atopic dermatitis. Am J Med. 2015;128:1325-34.e2. In this study coronary artery disease was measured by diagnostic imaging in patients with psoriasis and atopic dermatitis, respectively.

17. Su VY-F, Chen T-J, Yeh C-M, Chou K-T, Hung M-H, Chu S-Y, Su K-C, Chang Y-S, Lin Y-H, Liu C-J. Atopic dermatitis and risk of ischemic stroke: a nationwide population-based study. Ann Med. 2014:46:84-9.

18. Drucker AM, Li W-Q, Cho E, Li T, Sun Q, Camargo CA, Qureshi AA. Atopic dermatitis is not independently associated with nonfatal myocardial infarction or stroke among US women. Allergy. 2016; doi:10.1111/all.12957.

19. Andersen YMF, Egeberg A, Gislason GH, Hansen PR, Skov L, Thyssen JP. Risk of myocardial infarction, ischemic stroke, and cardiovascular death in patients with atopic dermatitis. J Allergy Clin Immunol. 2016;138:310-312.e3. This cohort study reported discrepencies in cardiovascular risk profiles in atopic dermatitis patients in Europe compared with observations in US and Asia.

20. Standl M, Tesch F, Baurecht H, et al. Association of atopic dermatitis with cardiovascular risk factors and diseases. J Invest Dermatol. 2016; doi:10.1016/j.jid.2016.11.031.

21. Radtke MA, Schäfer I, Glaeske G, Jacobi A, Augustin M. Prevalence and comorbidities in adults with psoriasis compared to atopic eczema. J Eur Acad Dermatology Venereol. 2016;171: e117-8.

22. Egeberg A, Andersen YMF, Gislason GH, Skov L, Thyssen JP. Prevalence of comorbidity and associated risk factors in adults with atopic dermatitis. Allergy. 2016; doi:10.1111/all.13085.

23. Thyssen JP, Linneberg A, Carlsen BC, et al. A possible association between a dysfunctional skin barrier (filaggrin null-mutation status) and diabetes: a cross-sectional study. BMJ Open. 2011;1:e00062.

24. Andersen YMF, Egeberg A, Gislason GH, Skov L, Knop FK, Thyssen JP. Adult atopic dermatitis and the risk of type 2 diabetes. J Allergy Clin Immunol. 2016. doi:10.1016/j.jaci.2016.08.049.

25. Lee JK, Park C, Kimm K, Rutherford MS. Genome-wide multilocus analysis for immune-mediated complex diseases. Biochem Biophys Res Commun. 2002;295:771-3. 
26. Donath MY, Shoelson SE. Type 2 diabetes as an inflammatory disease. Nat Rev Immunol. 2011;11:98-107.

27. Poetker DM, Reh DD. A comprehensive review of the adverse effects of systemic corticosteroids. Otolaryngol Clin N Am. 2010:43:753-68.

28. Hansson GK. Inflammation, atherosclerosis, and coronary artery disease. N Engl J Med. 2005;352:1685-95.

29. Novak N, Bieber T, Leung DYM. Immune mechanisms leading to atopic dermatitis. J Allergy Clin Immunol. 2003;112:128-39.

30. Kantor R, Kim A, Thyssen JP, Silverberg JI. Association of atopic dermatitis with smoking: a systematic review and meta-analysis. J Am Acad Dermatol. 2016;75:1119-1125.e1.

31. Olesen AB, Engholm G, Storm HH, Thestrup-Pedersen K. The risk of cancer among patients previously hospitalized for atopic dermatitis. J Invest Dermatol. 2005;125:445-9.

32. Jensen AO, Svaerke C, Körmendiné Farkas D, Olesen AB, Kragballe K, Sørensen HT. Atopic dermatitis and risk of skin cancer: a Danish nationwide cohort study (1977-2006). Am J Clin Dermatol. 2012;13:29-36.

33. Arana A, Wentworth CE, Fernández-Vidaurre C, Schlienger RG, Conde E, Arellano FM. Incidence of cancer in the general population and in patients with or without atopic dermatitis in the U.K. Br J Dermatol. 2010;163:1036-43.

34. Hagströmer L, Ye W, Nyrén O, Emtestam L. Incidence of cancer among patients with atopic dermatitis. Arch Dermatol. 2005;141: 1123-7.

35. Ming ME, Levy R, Hoffstad O, Filip J, Abrams BB, Fernández C, Margolis DJ. The lack of a relationship between atopic dermatitis and nonmelanoma skin cancers. J Am Acad Dermatol. 2004;50: 357-62.

36. Gandini S, Stanganelli I, Palli D, De Giorgi V, Masala G, Caini S. Atopic dermatitis, naevi count and skin cancer risk: a meta-analysis. J Dermatol Sci. 2016;84:137-43.

37. Mildner M, Jin J, Eckhart L, et al. Knockdown of filaggrin impairs diffusion barrier function and increases UV sensitivity in a human skin model. J Invest Dermatol. 2010;130:2286-94.

38. Elias PM, Williams ML. Comment on "does a history of eczema predict a future basal cell carcinoma?". J Invest Dermatol. 2013;133:1676-7.

39. Kaae J, Szecsi PB, Meldgaard M, et al. Individuals with complete filaggrin deficiency may have an increased risk of squamous cell carcinoma. Br J Dermatol. 2014;170:1380-1.

40. Jensen AØ, Thomsen HF, Engebjerg MC, Olesen AB, Friis S, Karagas MR, Sørensen HT. Use of oral glucocorticoids and risk of skin cancer and non-Hodgkin's lymphoma: a population-based case-control study. Br J Cancer. 2009;100:200-5.

41. Jiyad Z, Olsen CM, Burke MT, Isbel NM, Green AC. Azathioprine and risk of skin cancer in organ transplant recipients: systematic review and meta-analysis. Am J Transplant. 2016; doi:10.1111/ajt.13863.

42.• Legendre L, Barnetche T, Mazereeuw-Hautier J, Meyer N, Murrell D, Paul C. Risk of lymphoma in patients with atopic dermatitis and the role of topical treatment: a systematic review and meta-analysis. J Am Acad Dermatol. 2015;72:992-1002. This meta-analysis provides a thorogh summary of the current evidence on the relationship between atopic dermatitis, immunesuppressive therapy and the risk of lymphoma.

43. Josephs DH, Spicer JF, Corrigan CJ, Gould HJ, Karagiannis SN. Epidemiological associations of allergy, IgE and cancer. Clin Exp Allergy. 2013;43:1110-23.

44. Miyagaki T, Sugaya M. Erythrodermic cutaneous T-cell lymphoma: how to differentiate this rare disease from atopic dermatitis. J Dermatol Sci. 2011;64:1-6.

45. Linabery AM, Jurek AM, Duval S, Ross JA. The association between atopy and childhood/adolescent leukemia: a meta-analysis. Am J Epidemiol. 2010;171:749-64.
46. Wang M, Chen C, Qu J, Xu T, Lu Y, Chen J, Wu S. Inverse association between eczema and meningioma: a meta-analysis. Cancer Causes Control. 2011;22:1355-63.

47. Chen C, Xu T, Chen J, Zhou J, Yan Y, Lu Y, Wu S. Allergy and risk of glioma: a meta-analysis. Eur J Neurol. 2011;18:387-95.

48. Linos E, Raine T, Alonso A, Michaud D. Atopy and risk of brain tumors: a meta-analysis. J Natl Cancer Inst. 2007;99:1544-50.

49. Morgan TK, Hanifin J, Mahmood M, Larson B, Baig-Lewis S, Long T, Lim JY, Berlin M, Weese K. Atopic dermatitis is associated with cervical high risk human papillomavirus infection. J Low Genit Tract Dis. 2015;19:345-9.

50. Skaaby T, Husemoen LLN, Jørgensen T, Johansen JD, Menné T, Szecsi PB, Stender S, Bager P, Thyssen JP, Linneberg A. Associations of filaggrin gene loss-of-function variants and human papillomavirus-related cancer and pre-cancer in Danish adults. PLoS One. 2014;9:e99437.

51. Bager P, Wohlfahrt J, Sørensen E, et al. Common filaggrin gene mutations and risk of cervical cancer. Acta Oncol. 2015;54:217-23.

52. Cotterchio M, Lowcock E, Hudson TJ, Greenwood C, Gallinger S. Association between allergies and risk of pancreatic cancer. Cancer Epidemiol Biomark Prev. 2014;23:469-80.

53. Wang H, Diepgen TL. Atopic dermatitis and cancer risk. Br J Dermatol. 2006;154:205-10.

54. Jensen KE, Schmiedel S, Frederiksen K, Norrild B, Iftner T, Kjær SK. Risk for cervical intraepithelial neoplasia grade 3 or worse in relation to smoking among women with persistent human papillomavirus infection. Cancer Epidemiol Biomark Prev. 2012;21: 1949-55.

55. Kondo H, Soda M, Sawada N, Inoue M, Imaizumi Y, Miyazaki Y, Iwanaga M, Tanaka Y, Mizokami M, Tsugane S. Smoking is a risk factor for development of adult T-cell leukemia/lymphoma in Japanese human T-cell leukemia virus type-1 carriers. Cancer Causes Control. 2016;27:1059-66.

56. Fircanis S, Merriam P, Khan N, Castillo JJ. The relation between cigarette smoking and risk of acute myeloid leukemia: an updated meta-analysis of epidemiological studies. Am J Hematol. 2014;89: E125-32.

57. Wang L, Wang FS, Gershwin ME. Human autoimmune diseases: A comprehensive update. J Intern Med. 2015;278:369-95.

58. Mohan GC, Silverberg JI. Association of vitiligo and alopecia areata with atopic dermatitis: a systematic review and meta-analysis. JAMA dermatology. 2014;151:522-8.

59. Wu L-C, Hwang C-Y, Chung P-I, et al. Autoimmune disease comorbidities in patients with atopic dermatitis: a nationwide casecontrol study in Taiwan. Pediatr Allergy Immunol. 2014;25:58692.

60. Andersen YMF, Egeberg A, Gislason GH, Skov L, Thyssen JP. Autoimmune diseases in adults with atopic dermatitis. J Am Acad Dermatol. 2016; doi:10.1016/j.jaad.2016.08.047.

61. Kim M, Choi KH, Hwang SW, Lee YB, Park HJ, Bae JM. Inflammatory bowel disease is associated with an increased risk of inflammatory skin diseases: a population-based cross-sectional study. J Am Acad Dermatol. 2016; doi:10.1016/j. jaad.2016.08.022.

62. Schmitt J, Schwarz K, Baurecht H, et al. Atopic dermatitis is associated with an increased risk for rheumatoid arthritis and inflammatory bowel disease, and a decreased risk for type 1 diabetes. J Allergy Clin Immunol. 2016;137:130-6. This study reported the association between atopic dermatitis and three important autoimmune diseases in a large population and in genotyped data.

63. Niwa Y, Sumi H, Akamatsu H. An association between ulcerative colitis and atopic dermatitis, diseases of impaired superficial barriers. J Invest Dermatol. 2004;123:999-1000.

64. Ress K, Annus T, Putnik U, Luts K, Uibo R, Uibo O. Celiac disease in children with atopic dermatitis. Pediatr Dermatol. 2014;31:483-8. 
65. Ciacci C, Cavallaro R, Iovino P, Sabbatini F, Palumbo A, Amoruso D, Tortora R, Mazzacca G. Allergy prevalence in adult celiac disease. J Allergy Clin Immunol. 2004;113:1199-203.

66. Hsiao YP, Tsai JD, Muo CH, Tsai CH, Sung FC, Liao YT, Chang YJ, Yang JH. Atopic diseases and systemic lupus erythematosus: an epidemiological study of the risks and correlations. Int J Environ Res Public Health. 2014;11:8112-22.

67. Wei C-C, Lin C-L, Tsai J-D, Shen T-C, Sung F-C. Increased incidence of juvenile onset systemic lupus erythematosus in children with atopic dermatitis. Lupus. 2014;23:1494-9.

68. Rudwaleit M, Andermann B, Alten R, Sorensen H, Listing J, Zink A, Sieper J, Braun J. Atopic disorders in ankylosing spondylitis and rheumatoid arthritis. Ann Rheum Dis. 2002;61:968-74.

69. Monteiro L, Souza-Machado A, Menezes C, Melo A. Association between allergies and multiple sclerosis: a systematic review and meta-analysis. Acta Neurol Scand. 2011;123:1-7.

70. Cardwell CR, Shields MD, Carson DJ, Patterson CC. A metaanalysis of the association between childhood type 1 diabetes and atopic disease. Diabetes Care. 2003;26:2568-74.

71. Pedullá M, Fierro V, Papacciuolo V, Alfano R, Ruocco E. Atopy as a risk factor for thyroid autoimmunity in children affected with atopic dermatitis. J Eur Acad Dermatology Venereol. 2014;28:1057-60.

72. Salsano ME, Graziano L, Luongo I, Pilla P, Giordano M, Lama G. Atopy in childhood idiopathic nephrotic syndrome. Acta Paediatr Int J Paediatr. 2007;96:561-6.

73. Lin CY, Lee BH, Lin CC, Chen WP. A study of the relationship between childhood nephrotic syndrome and allergic diseases. Chest. 1990;97:1408-11.

74. Wei C-C, Lin C-L, Shen T-C, Li T-C, Chen A-C. Atopic dermatitis and association of risk for Henoch-Schönlein purpura (IgA Vasculitis) and renal involvement among children: results from a population-based cohort study in Taiwan. Medicine (Baltimore). 2016;95:e2586.

75.• Paternoster L, Standl M, Waage J, et al. Multi-ancestry genomewide association study of 21,000 cases and 95,000 controls identifies new risk loci for atopic dermatitis. Nat Genet. 2015;47:144956. This study identified new atopic dermatitis risk loci with candidate genes that may influence immune regulation, suggesting an autoimmune component in atopic dermatitis patophysiology.

76. Mackay IR. Clustering and commonalities among autoimmune diseases. J Autoimmun. 2009;33:170-7.

77. Tang TS, Bieber T, Williams HC. Does “autoreactivity" play a role in atopic dermatitis? J Allergy Clin Immunol. 2012;129:1209-15.

78. Costenbader KH, Karlson EW. Cigarette smoking and autoimmune disease: what can we learn from epidemiology? Lupus. 2006;15: $737-45$.

79. Jakobsen C, Paerregaard A, Munkholm P, Wewer V. Environmental factors and risk of developing paediatric inflammatory bowel diseasea population based study 2007-2009. J Crohn's Colitis. 2013;7:79-88.

80. Whiteley J, Emir B, Seitzman R, Makinson G. The burden of atopic dermatitis in U.S. adults: results from the 2013 National Health and Wellness Survey. Curr Med Res Opin. 2016;7995:1-32.

81. Yu SH, Silverberg JI. Association between atopic dermatitis and depression in US adults. J Invest Dermatol. 2015;135:3183-6.
82. Yaghmaie P, Koudelka CW, Simpson EL. Mental health comorbidity in patients with atopic dermatitis. J Allergy Clin Immunol. 2013;131:428-33.

83. Kimata H. Prevalence of suicidal ideation in patients with atopic dermatitis. Suicide Life Threat Behav. 2006;36:120-4.

84. Dieris-Hirche J, Gieler U, Kupfer JP, Milch WE. Suizidgedanken, Angst und Depression bei erwachsenen Neurodermitikern. Hautarzt. 2009;60:641-6.

85. Zachariae R, Zachariae C, Ibsen HHW, Mortensen JT, Wulf HC. Psychological symptoms and quality of life of dermatology outpatients and hospitalized dermatology patients. Acta Derm Venereol. 2004;84:205-12.

86. Egeberg A, Hansen PR, Gislason GH, Skov L, Mallbris L (2016) Risk of self-harm and non-fatal suicide attempts, and completed suicide in patients with psoriasis - a population-based cohort study. Br J Dermatol

87. Cheng C-M, Hsu J-W, Huang K-L, et al. Risk of developing major depressive disorder and anxiety disorders among adolescents and adults with atopic dermatitis: a nationwide longitudinal study. J Affect Disord. 2015;178:60-5.

88. Oh SH, Bae BG, Park CO, Noh JY, Park IH, Wu WH, Lee KH. Association of stress with symptoms of atopic dermatitis. Acta Derm Venereol. 2010;90:582-8.

89. Camfferman D, Kennedy JD, Gold M, Martin AJ, Lushington K. Eczema and sleep and its relationship to daytime functioning in children. Sleep Med Rev. 2010;14:359-69.

90. Wittkowski A, Richards HL, Griffiths CEM, Main CJ. The impact of psychological and clinical factors on quality of life in individuals with atopic dermatitis. J Psychosom Res. 2004;57:195-200.

91. Yu SH, Attarian H, Zee P, Silverberg JI. Burden of sleep and fatigue in US adults with atopic dermatitis. Dermat contact, atopic, Occup drug. 2016;27:50-8.

92. Drucker AM, Wang AR, Li W-Q, Sevetson E, Block JK, Qureshi AA. The burden of atopic dermatitis: summary of a report for the National Eczema Association. J Invest Dermatol. 2016; doi:10.1016/j.jid.2016.07.012.

93. Nyggard U, Riss JL, Deleuran M, Vestergaard C. Attention-deficit/ hyperactivity disorder in atopic dermatitis. An appraisal of the current literature. Pediatr Allergy, Immunol Pulmonol. 2016;29:181-8. This recently published review article concludes that children with atopic dermatitis have a 1.5 fold increased risk of attention deficit hyperactivity disorder based on the current evidence.

94. Billeci L, Tonacci A, Tartarisco G, Ruta L, Pioggia G, Gangemi S. Association between atopic dermatitis and autism spectrum disorders: a systematic review. Am J Clin Dermatol. 2015;16:371-88.

95. Buske-Kirschbaum A, Schmitt J, Plessow F, Romanos M, Weidinger $\mathrm{S}$, Roessner V. Psychoendocrine and psychoneuroimmunological mechanisms in the comorbidity of atopic eczema and attention deficit/hyperactivity disorder. Psychoneuroendocrinology. 2013;38: 12-23. This review article highlights possible mechanisms of neuroinflammation that may contribute to the risk of neuropsychiatric disorders in patients with atopic dermatitis.

96. Hanc T, Szwed A, Slopien A, Wolanczyk T, Dmitrzak-Weglarz M, Ratajczak J. Perinatal risk factors and ADHD in children and adolescents: a hierarchical structure of disorder predictors. J Atten Disord. 2016; doi:10.1177/1087054716643389. 